\title{
Existential attitudes and Occupational burnout syndrome in nurses
}

Postawy egzystencjalne a syndrom wypalenia zawodowego pielęgniarek

Anna Mazur ${ }^{1}$, Anna Goś2 ${ }^{2}$ Ewa Humeniuk ${ }^{1}$

'Zakład Patologii i Rehabilitacji Mowy, Wydział Nauk o Zdrowiu, Uniwersytet Medyczny w Lublinie ${ }^{2}$ Studium Praktycznej Nauki Języków Obcych, I Wydział Lekarski z Oddziałem Stomatologicznym, Uniwersytet Medyczny w Lublinie

AUTOR DO KORESPONDENCJI/CORRESPONDING AUTHOR:

Anna Mazur

e-mail: annamazur10@02.pl

\section{STRESZCZENIE EXISTENIIAL ATTHTUDES AND OCCUPATIONAL BURNOUT SYNDROME IN NURSES}

Cel pracy. Celem pracy jest określenie zależności występujących pomiędzy postawami egzystencjalnymi a syndromem wypalenia zawodowego pielęgniarek.

Materiał i metodyka. Zbadano 120 pielęgniarek wykorzystując Kwestionariusz Postaw Życiowych KPŻ w adaptacji R. Klamuta oraz Kwestionariusz Wypalenia Zawodowego LBQ w adaptacji A. Jaworowskiej.

Wyniki. Wyczerpanie psychofizyczne i brak zaangażowania w relacje z klientami ujemnie koreluje z celem, spójnością wewnętrzną, kontrolą życia, akceptacją śmierci oraz dodatnio z pustką egzystencjalną i z poszukiwaniem celów. Poczucie braku skuteczności zawodowej i rozczarowanie wykazuje odwrotnie proporcjonalny związek z celem, koherencją, kontrolą życia, a także pozytywny z pustką egzystencjalną i z poszukiwaniem celów.

Wnioski. Wykonane analizy wykazały, iż postawy egzystencjalne współwystępują z wypaleniem zawodowym pielęgniarek. Uzyskane rezultaty badań własnych mają znaczenie poznawcze oraz mogą być wykorzystane do opracowania programów profilaktycznych i pomocowych wspierających jakość osobistego i zawodowego funkcjonowania pielęgniarek.

Słowa kluczowe: postawy egzystencjalne, syndrom wypalenia zawodowego, pielęgniarki

ABSTRACT POSTAWY EGZYSTENCJALNE A SYNDROM WYPALENIA ZAWODOWEGO PIELEGGNAREK

Aim. The aim of the study was to determine the relation between existential attitudes and occupational burnout in nurses.

Material and methods. The research sample consisted of 120 nurses. Life Attitudes Profile - Revised (the LAP-R) adapted by R. Klamut and Link Burnout Questionnaire (the LBQ) adapted by A. Jaworowska were used in the research.

Results. Psycho-physical exhaustion and relationship deterioration correlate negatively with life goals, internal consistency, life control, death acceptance and positively with existential void and goal seeking. Sense of professional failure and disillusion present a conversely proportional relation with goal, coherence, life control as well as an inversely proportional relation with existential void and goal seeking.

Conclusions. The analyses performed in the course of the research proved that existential attitudes accompany burnout in nurses. The obtained results of the authors' own research present cognitive value and can be used to develop both prevention and aid programs aimed at enhancing the quality of personal and professional functioning of nurses.

Key words: existential attitudes, 0 ccupational burnout, nurses

\section{INTRODUCTION}

Burnout can happen to employees of all kinds. However, individuals who are the most particularly prone to burnout include professionals that provide help for others. Nurses belong to a professional group at high risk of burnout, since they experience stress at work due to significant burdens and the need for provision of assistance for patients [1-6].
Occupational burnout is defined as a syndrome of psychological symptoms that occur in employees who experience chronic occupational stress that results from the lack of balance between the burdens and personal resources [7]. Symptoms of burnout include psychophysical exhaustion, relationship deterioration, sense of professional ineffectiveness and disillusion. Psychophysical exhaustion is manifested through a decreased level 
of individual's psychophysical resources, fatigue, pressure and tension. Relationship deterioration defines the quality of relationship with patients or charges. It is shown in instrumental attitude towards patients, indifference and distance to their needs and even hostility. The sense of professional ineffectiveness means perceiving one's work as ineffective, whereas disillusion is characterized by a conviction that an individual's professional activity differs significantly from their personal expectations, values and does not present perspectives for development $[1,5,7]$.

Both preventive and therapeutic measures targeted at people suffering from the syndrome should focus on enhancing the protective factors and modifying the risk factors [1-2].

Thus, one of the areas that require further exploration is verifying whether existential attitudes are linked to burnout in nurses, as well as distinguishing factors that protect and predispose to occupational burnout.

According to Reker [8], existential attitudes express the notion of sense which involves three components: affective, cognitive and motivational. Affective component is expressed by the sense of personal satisfaction from the activities that make sense in life. Cognitive component is responsible for attributing meaning to various events, organizing experiences as well as creating beliefs concerning the existence of the subject. At the same time, the motivational component is characterized by the ability to undertake tasks that enable the attainment of goals in line with ones values and find sense in life. [9].

Reker distinguished the following six and basic existential attitudes: purpose, internal coherence, death acceptance, life control, existential void and goal-seeking. The attitude of purposefulness is defined as staying focused on the future, having goals in life, as well as an individual's knowledge on what is essential in life. Internal coherence refers to the level of an individual's integrity, their ability to understand themselves and surrounding reality. Life control is characterised by a conviction that having an influence on one's own life and readiness to accept responsibility for it. Death acceptance allows the determination of the extent of understanding and accepting death as an inevitable event in life. Existential void refers to the feeling of depression, boredom, indifference and lack of sense in life. Whereas, goal-seeking is manifested by striving for changes in life [10].

\section{AIM}

The aim of the study is to determine the relation between existential attitudes and Occupational burnout in nurses?

\section{MATERIAL AND METHODS}

The research sample was collected on the basis of intentional choice and consisted of 120 nurses working in primary care settings. The average age of the surveyed was above 44 years old $(\mathrm{M}=44.51 ; \mathrm{SD}=15.09)$. The average employment period of the surveyed lasted more than 15 years $(\mathrm{M}=15.37$; $\mathrm{SD}=8.84)$.
G. Reker's Life Attitudes Profile-Revised (the LAP-R) adapted by R. Klamut, as well as M. Santinello's Link Burnout Questionnaire (the LBQ) adapted by A. Jaworowska were used in the research [12]. The Life Attitudes Profile-Revised (the LAP-R) is used to measure the notion of sense of life and the level of motivation to make one's life meaningful and formulate goals. The research tool consists of six basic scales that refer to various life attitudes and they comprise Purpose, Internal coherence, Life control, Death acceptance, Existential void and Goal seeking [11]. The Link Burnout Questionnaire is designed to diagnose the rate of burnout in people working in social professions which involve direct interaction with people. The tool four scales that enable the measurement of different aspects of burnout, namely Psychophysical exhaustion, Relationship deterioration, Sense of professional ineffectiveness and Disillusion [12].

The research was voluntary, individual and anonymous. It was conducted in accordance with the Declaration of Helsinki. The surveyed were informed about the purpose and course of the research and agreed to participate in it. Statistical calculations were performed using the IBM SPSS 21 software. The description of the sample was based on the calculation of descriptive statistics of quantitative variables. Due to the linear character of dependencies between the investigated variables, Pearson's $r$ coefficient was used to perform correlation analyses.

\section{RESULTS}

The analyses performed in the course of the research indicate that existential attitudes accompany occupational burnout syndrome in nurses. The results obtained are presented in table 1 .

Tab. 1. The Values of correlation coefficients between existential attitudes and occupational burnout in nurses.

\begin{tabular}{|l|c|c|c|c|}
\hline Variables & $\begin{array}{c}\text { Psychophysical } \\
\text { exhaustion }\end{array}$ & $\begin{array}{c}\text { Relationship } \\
\text { deterioration }\end{array}$ & $\begin{array}{c}\text { Sense of } \\
\text { professional } \\
\text { ineffectiveness }\end{array}$ & Disillusion \\
\hline Purpose & $-0.51^{* *}$ & $-0.55^{* *}$ & $-0.64^{* *}$ & $-0.50^{* *}$ \\
\hline $\begin{array}{l}\text { Internal } \\
\text { coherence }\end{array}$ & $-0.35^{* *}$ & $-0.43^{* *}$ & $-0.54^{* *}$ & $-0.33^{* *}$ \\
\hline Life control & $-0.19^{*}$ & $-0.29^{* *}$ & $-0.33^{* *}$ & $-0.21^{*}$ \\
\hline $\begin{array}{l}\text { Death } \\
\text { acceptance }\end{array}$ & $-0.21^{*}$ & $-0.27^{* *}$ & -0.08 & -0.09 \\
\hline $\begin{array}{l}\text { Existential } \\
\text { void }\end{array}$ & $0.43^{* *}$ & $0.48^{* *}$ & $0.41^{* *}$ & $0.40^{* *}$ \\
\hline Goal seeking & $0.49^{* *}$ & $0.46^{* *}$ & $0.39^{* *}$ & $0.43^{* *}$ \\
\hline
\end{tabular}

** correlation significant at $0.01 ;{ }^{*}$ correlation significant at 0.05

The calculations prove there is a strong negative correlation between the purpose and psychophysical exhaustion, relationship deterioration, sense of professional ineffectiveness. There is also an average relationship with disillusion. The obtained data imply that the rate of psychophysical exhaustion, tendency to treat patients instrumentally, sense of professional ineffectiveness as well as disillusion decrease along with the increase 
in nurses' conviction of what is important in their lives. Internal coherence shows strong inversely proportional dependency with sense of professional ineffectiveness and average negative dependency with psychophysical exhaustion, relationship deterioration and disillusion. The results obtained suggest that the higher the rate of an individual's integrity, the lower the psychophysical exhaustion, tendency not to notice patients' individual needs, conviction of the lack of professional effectiveness or negative perceptions of the occupation. Life control weakly negatively correlates with psychophysical exhaustion and relationship deterioration as well as averagely negatively with the sense of professional ineffectiveness and disillusion which indicates that the feeling of tension, tiredness and exhaustion, treating patients instrumentally, conviction of professional ineffectiveness and disillusion decrease with the increase in the belief that they have an influence on their lives. Death acceptance shows weak inversely proportional dependency with psychophysical exhaustion and relationship deterioration. The data suggest that the higher the comprehension and acceptance of death as an inevitable phenomenon, the lower the feeling of loss of psychophysical resources and indifference towards patients. Existential void as well as goal seeking are averagely positively connected with psychophysical exhaustion, relationship deterioration, sense of professional ineffectiveness and disillusion. The results obtained illustrate that each of the four symptoms of burnout in nurses increases along with the increase in the lack of sense in life, experiencing boredom and indifference, as well as conviction of the need for the introduction of life changes. The correlation analyses did not reveal statistically significant relations between the remaining dimensions of existential attitudes and burnout in nurses.

\section{DISCUSSION}

The aim of the authors' research was to determine relations between existential attitudes and occupational burnout syndrome in nurses. The analyses performed proved that psychophysical exhaustion and relationship deterioration are negatively related to the attitude of purposefulness, internal coherence, life control, death acceptance and positively correlated with existential void and goal seeking. Whereas, sense of professional ineffectiveness and disillusion indicate inversely proportional relation with purpose, internal coherence, life control as well as positive correlation with existential void and goal seeking.

The results of the authors' research emphasise significance of life attitudes for the occurrence of burnout in nurses. They also indicate that having life goals, sense of coherence, conviction of having control over one's life and death acceptance are factors protecting from psychophysical exhaustion and relationship deterioration. The attitude of purposefulness, internal coherence and life control play a protective role in terms of professional ineffectiveness and disillusion. Whereas, burnout risk factors involve the sense of existential void as well as goal seeking.

There were various empirical studies analyzing the factors linked to burnout in nurses. Research teams represented by Durkin, Beaumont, Hollins and Carson [13], Kolthoff and Hickman [14] as well as Lee and Seomun [15] demonstrated that compassion expressed by nurses both to themselves and others positively coexists with their wellbeing and negatively with burnout. Vander, Cavents, Daneels et al. [16] proved that the emotional demands faced by nurses and their work engagement play a crucial role in developing occupational burnout. Whereas, resistance resources, especially social support, are factors that protect from burnout. Interesting research by Admi and Eilon-Moshe [17] indicated that the most stressful factors that determine burnout in nurses encompass perceived professional responsibility and lack of sufficient abilities to cope with it.

\section{CONCLUSIONS}

1. Existential attitudes coexist with burnout in nurses.

2. Psychophysical exhaustion and relationship deterioration are negatively related to purpose, internal coherence, life control, death acceptance and positively related with existential void and goal seeking.

3. The sense of professional ineffectiveness and disillusion show negative relations with purpose, internal coherence, life control as well as positive relation with existential void and goal seeking.

4. Existential attitudes that inversely proportionally relate with burnout serve as factors protecting from the syndrome.

5. Existential attitudes that are positively related with burnout can intensify the risk of the syndrome.

6. The results of the authors' research are of great cognitive significance and can be applied to the development of preventive and aid programs, enhancing the quality of personal and professional functioning of nurses. 


\section{Postawy egzystencjalne a syndrom wypalenia zawodowego pielęgniarek}

\section{WPROWADZENIE}

Syndrom wypalenia zawodowego może pojawić się u osób zatrudnionych na różnych stanowiskach. Szczególnie, jednak, narażone są na niego jednostki wykonujące pracę związaną z udzielaniem pomocy innym. Do takiej grupy zawodowej należą pielęgniarki, które na skutek doświadczanego w pracy stresu, wynikającego ze znacznych obciążeń oraz z konieczności niesienia pomocy chorym ludziom, znajdują się w grupie podwyższonego ryzyka wystąpienia wymienionego zespołu [1-6].

Syndrom wypalenia zawodowego jest definiowany jako zespół psychologicznych objawów pojawiających się u pracownika z powodu doświadczania przewlekłego stresu, będącego konsekwencją braku równowagi między osobistymi zasobami a obciążeniami [7]. Wyróżnia się cztery jego symptomy: wyczerpanie psychofizyczne, brak zaangażowania $\mathrm{w}$ relacje $\mathrm{z}$ klientami, poczucie braku skuteczności zawodowej oraz rozczarowanie. Wyczerpanie psychofizyczne wyraża się jako obniżony poziom psychofizycznych zasobów jednostki oraz wiążące się z nim poczucie zmęczenia, presji i napięcie. Brak zaangażowania w relacje z klientem określa jakość relacji z pacjentami lub podopiecznymi. Ujawnia się pod postacią przedmiotowego podejścia do klientów, obojętności i dystansu wobec ich potrzeb, a nawet wrogości. Poczucie braku skuteczności zawodowej oznacza postrzeganie swojej pracy jako nieefektywnej, a rozczarowanie charakteryzuje przeświadczenie, iż realizowana aktywność zawodowa zdecydowanie odbiega od osobistych oczekiwań, wyznawanych wartości oraz nie stwarza szansy na rozwój $[1,5,7]$.

W działaniach profilaktycznych ukierunkowanych na zapobieganie wypaleniu zawodowemu oraz terapeutycznych skierowanych do osób, u których pojawił się już omawiany syndrom, istotne jest skoncentrowanie się na wzmocnieniu czynników chroniących oraz zmodyfikowaniu czynników ryzyka [1-2].

W tym kontekście należy zaznaczyć, iż jednym, z obszarów wymagającym dalszej eksploracji jest zweryfikowanie, czy postawy egzystencjalne są powiązane $\mathrm{z}$ wypaleniem zawodowym pielęgniarek oraz wyodrębnienie spośród nich czynników chroniących oraz predysponujących do wystąpienia powyższego syndromu.

Postawy egzystencjalne w ujęciu Rekera [8] wyrażają poczucie sensu życia, na które składają się trzy komponenty: afektywny, poznawczy i motywacyjny. Komponent afektywny przejawia się pod postacią poczucia osobistej satysfakcji z realizacji działań nadających życiu człowieka sens. Komponent poznawczy odpowiada za przypisywanie znaczenia różnym wydarzeniom, porządkowanie doświadczeń, a także za kształtowanie przekonań na temat egzystencji podmiotu. Natomiast, komponent motywacyjny charakteryzuje zdolność do podejmowania się zadań pozwalających realizować zgodne z wyznawanymi wartościami cele, a także umożliwiających odnalezienie sensu życia [9].
Reker wyróżnił sześć podstawowych postaw egzystencjalnych: cel, spójność wewnętrzną, akceptację śmierci, kontrolę życia, pustkę egzystencjalną i poszukiwanie celów. Postawa celowości określa ukierunkowanie na przyszłość, posiadanie życiowych celów oraz wiedzę człowieka na temat tego, co jest istotne w jego życiu. Spójność wewnętrzna opisuje poziom koherencji, zintegrowania jednostki, jej zdolność do rozumienia siebie oraz otaczającej rzeczywistości. Kontrola życia charakteryzuje przekonanie o posiadaniu wpływu na własne życie i gotowość do przyjmowania za nie odpowiedzialności. Akceptacja śmierci pozwala określić stopień zrozumienia i zaakceptowania śmierci, jako nieuchronnego wydarzenia życiowego. Pustka egzystencjalna odnosi się do poczucia przygnębienia, nudy, obojętności oraz braku sensu życia. Natomiast, poszukiwanie celów przejawia się w dążeniu do dokonywania życiowych zmian [10].

\section{CEL PRACY}

Celem pracy jest określenie zależności występujących pomiędzy postawami egzystencjalnymi a syndromem wypalenia zawodowego pielęgniarek.

\section{MATERIAŁ I METODYKA}

Próbę badaną utworzono w oparciu o dobór celowy i tworzy ją 120 pielęgniarek pracujących w zakładach podstawowej opieki zdrowotnej. Średni wiek diagnozowanych wynosi powyżej 44 lat $(M=44,51 ; S D=15,09)$. Przeciętna długość stażu pracy badanych to ponad 15 lat $(\mathrm{M}=15,37$; $\mathrm{SD}=8,48)$.

W badaniach wykorzystano Kwestionariusz Postaw Życiowych KPŻ G. Rekera w polskiej adaptacji R. Klamuta [11] oraz Kwestionariusz Wypalenia Zawodowego LBQ M. Santinello w polskiej adaptacji A. Jaworowskiej [12]. Kwestionariusz Postaw Życiowych KPŻ służy do badania poczucia sensu życia oraz poziomu motywacji do nadawania swojemu życiu sensu i formułowania celu. Narzędzie obejmuje sześć skal prostych, dotyczących różnych postaw życiowych. Należą do nich: Cel, Spójność wewnętrzna, Kontrola życia, Akceptacja śmierci, Pustka egzystencjalna i Poszukiwanie celów [11]. Kwestionariusz Wypalenia Zawodowego LBQ jest przeznaczony do diagnozy poziomu wypalenia zawodowego u osób pracujących $\mathrm{w}$ zawodach społecznych, które wiążą się z koniecznością wchodzenia $w$ bezpośrednie interakcje $\mathrm{z}$ innymi ludźmi. Narzędzie zawiera cztery skale pozwalające zbadać różne aspekty wypalenia zawodowego: Wyczerpanie psychofizyczne, Brak zaangażowania w relacje z klientami, Poczucie braku skuteczności zawodowej oraz Rozczarowanie z wykonywanej pracy [12].

Badania miały charakter dobrowolny, indywidualny i anonimowy. Zostały przeprowadzone zgodnie z założeniami Deklaracji Helsińskiej. Osoby diagnozowane zostały 
poinformowane o celu i przebiegu badań oraz zgodziły się wziąć w nich udział. Obliczenia statystyczne wykonano za pomocą programu statystycznego IBM SPSS 21. Charakterystykę próby oparto na obliczeniu statystyk opisowych zmiennych ilościowych. Do przeprowadzenia analiz korelacyjnych, z uwagi na liniowy charakter powiązań między rozpatrywanymi zmiennymi, zastosowano współczynnik $r$ Pearsona.

\section{WYNIKI}

Przeprowadzone analizy wykazały, że postawy egzystencjalne współwystępują $\mathrm{z}$ syndromem wypalenia zawodowego pielęgniarek. Uzyskane wyniki przedstawiono w tabeli 1.

Tab. 1. Wartości współczynników korelacji między postawami egzystencjalnymi a syndromem wypalenia zawodowego pielęgniarek.

\begin{tabular}{|c|c|c|c|c|}
\hline Zmienne & 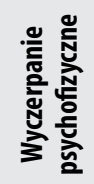 & $\begin{array}{c}\text { Brak } \\
\text { zaangażowania } \\
\text { w relacje } \\
\text { z klientami }\end{array}$ & $\begin{array}{l}\text { Poczucie braku } \\
\text { skuteczności } \\
\text { zawodowej }\end{array}$ & 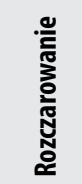 \\
\hline Cel & $-0.51^{* * *}$ & $-0.55^{* *}$ & $-0.64^{* *}$ & $-0.50^{* *}$ \\
\hline $\begin{array}{l}\text { Spójność } \\
\text { wewnętrzna }\end{array}$ & $-0.35^{* *}$ & $-0.43^{* *}$ & $-0.54^{* *}$ & $-0.33^{* *}$ \\
\hline Kontrola życia & $-0.19^{*}$ & $-0.29 * *$ & $-0.33^{* *}$ & $-0.21^{*}$ \\
\hline $\begin{array}{l}\text { Akceptacja } \\
\text { śmierci }\end{array}$ & $-0.21^{*}$ & $-0.27^{* *}$ & -0.08 & -0.09 \\
\hline $\begin{array}{l}\text { Pustka } \\
\text { egzystencjalna }\end{array}$ & $0.43^{* *}$ & $0.48^{* *}$ & $0.41^{* *}$ & $0.40^{* *}$ \\
\hline $\begin{array}{l}\text { Poszukiwanie } \\
\text { celów }\end{array}$ & $0.49^{* *}$ & $0.46^{* *}$ & $0.39^{* *}$ & $0.43^{* *}$ \\
\hline
\end{tabular}

** korelacja istotna na poziomie 0,$01 ;{ }^{*}$ korelacja istotna na poziomie 0,05

Wykonane obliczenia dowodzą, iż cel silnie ujemnie współwystępuje $\mathrm{z}$ wyczerpaniem psychofizycznym, brakiem zaangażowania $\mathrm{w}$ relacje $\mathrm{z}$ pacjentem, poczuciem braku skuteczności zawodowej, a także przeciętnie ujemnie z rozczarowaniem z pracy zawodowej. Uzyskane dane oznaczają, że wraz ze wzrostem przekonania pielęgniarek na temat tego, co jest ważne w ich życiu, obniża się poziom wyczerpania ich zasobów psychofizycznych, skłonność do przedmiotowego podejścia do pacjentów, poczucie porażki zawodowej, a także maleje rozczarowanie $\mathrm{z}$ wykonywanej pracy zawodowej. Spójność wewnętrzna wykazuje silną odwrotnie proporcjonalną zależność $\mathrm{z}$ poczuciem braku skuteczności zawodowej oraz przeciętną ujemną z wyczerpaniem psychofizycznym, brakiem zaangażowania $w$ relacje z pacjentem i z rozczarowaniem. Otrzymane wyniki sugerują, że im wyższe zintegrowanie jednostki, tym niższe wyczerpanie psychofizyczne, tendencje do niedostrzegania indywidualnych potrzeb pacjentów, przekonanie o braku skuteczności zawodowej oraz negatywne postrzeganie wykonywanej pracy zawodowej. Kontrola życia słabo ujemnie koreluje $\mathrm{z}$ wyczerpaniem psychofizycznym oraz $\mathrm{z}$ brakiem zaangażowania $\mathrm{w}$ relacje $\mathrm{z}$ klientem, a także przeciętnie ujemnie z poczuciem braku skuteczności zawodowej i z rozczarowaniem, co wskazuje, że wraz ze wzrostem przekonania o posiadaniu wpływu na swoje życie obniża się poczucie napięcia, zmęczenia i wyczerpania, przedmiotowe podejście do pacjentów, przekonanie o braku efektów z wykonywanej pracy oraz rozczarowanie. Akceptacja śmierci wykazuje słabą odwrotnie proporcjonalną zależność z wyczerpaniem psychofizycznym oraz $\mathrm{z}$ brakiem zaangażowania $\mathrm{w}$ relacje $\mathrm{z}$ klientem. Uzyskane dane sugerują, iż im wyższe jest zrozumienie i zaakceptowanie śmierci jako nieuchronnego zjawiska, tym niższe jest poczucie utraty psychofizycznych zasobów oraz obojętność wobec pacjentów. Pustka egzystencjalna oraz poszukiwanie celów są przeciętnie dodatnio powiązane $\mathrm{z}$ wyczerpaniem psychofizycznym, brakiem zaangażowania $\mathrm{w}$ relacje $\mathrm{z}$ klientami, poczuciem braku skuteczności zawodowej i z rozczarowaniem. Otrzymane rezultaty wskazują, że wraz ze wzrostem poczucia braku sensu w życiu, doświadczania nudy i obojętności, a także stopnia przekonania o konieczności dokonania życiowych zmian, wzrasta każdy z czterech symptomów składających się na syndrom wypalenia zawodowego pielęgniarek. Przeprowadzone analizy korelacyjne nie ujawnily istotnych statystycznie powiązań pomiędzy pozostałymi wymiarami postaw egzystencjalnych a wypaleniem zawodowym pielęgniarek.

\section{DYSKUSJA}

Celem badań własnych było określenie zależności występujących pomiędzy postawami egzystencjalnymi a syndromem wypalenia zawodowego pielęgniarek. Przeprowadzone analizy wykazały, iż wyczerpanie psychofizyczne i brak zaangażowania $\mathrm{w}$ relacje $\mathrm{z}$ klientami są ujemnie powiązane z postawą celowości, spójnością wewnętrzną, kontrolą życia, akceptacją śmierci oraz dodatnio z pustką egzystencjalną i z poszukiwaniem celów. Z kolei, poczucie braku skuteczności zawodowej i rozczarowanie wykazują odwrotnie proporcjonalny związek z celem, spójnością wewnętrzną, kontrolą życia, a także pozytywny z pustką egzystencjalną i z poszukiwaniem celów.

Otrzymane wyniki badań własnych podkreślają znaczenie życiowych postaw człowieka dla występowania syndromu wypalenia zawodowego $\mathrm{w}$ środowisku pielęgniarek. Pozwalają również wskazać, iż czynnikami chroniącymi przed pojawieniem się wyczerpania psychofizycznego i unikaniem zaangażowania $w$ relacje z pacjentami jest posiadanie życiowych celów, poczucie koherencji, przekonanie o sprawowaniu kontroli nad swym życiem i akceptacja śmierci. W przypadku poczucia braku skuteczności zawodowej oraz rozczarowania $\mathrm{z}$ wykonywanej pracy ochronną rolę pełni postawa celowości, spójność wewnętrzna i kontrola życia. Natomiast, do czynników ryzyka omawianego syndromu należy poczucie pustki egzystencjalnej, a także poszukiwanie celów.

Analizie czynników powiązanych $\mathrm{z}$ wypaleniem zawodowym pielęgniarek poświęcono wiele prac empirycznych. Zespoły badawcze Durkin, Beaumont, Hollins i Carson [13], Kolthoff i Hickman [14] oraz Lee i Seomun [15] wykazały, iż okazywane, przez pielęgniarki, współczucie sobie oraz innym dodatnio współwystępuje z ich 
dobrym samopoczuciem i ujemnie $\mathrm{z}$ wypaleniem zawodowym. Vander, Cavents, Daneels et al. [16] dowiedli, iż decydującą rolę przy powstawaniu wypalenia zawodowego pielęgniarek pełnią stawiane im emocjonalne wymagania oraz zaangażowanie w wykonywaną pracę. Z kolei, zasoby odpornościowe, w tym przede wszystkim wsparcie społeczne, są czynnikami zabezpieczającymi przed wystąpieniem wypalenia. Interesujace badania przeprowadzili również Admi i Eilon-Moshe [17], którzy wskazali, iż najbardziej stresującymi czynnikami determinującymi wypalenie zawodowe pielęgniarek są postrzegany ciężar odpowiedzialności zawodowej oraz brak wystarczających umiejętności do radzenia sobie z nim.

\section{WNIOSKI}

1. Postawy egzystencjalne współwystępują z syndromem wypalenia zawodowego pielęgniarek.

2. Wyczerpanie psychofizyczne i brak zaangażowania $\mathrm{w}$ relacje z pacjentami są ujemnie powiązane $\mathrm{z}$ celem, spójnością wewnętrzną, kontrolą życia, akceptacją śmierci oraz dodatnio $\mathrm{z}$ pustką egzystencjalną i z poszukiwaniem celów.

3. Poczucie braku skuteczności zawodowej i rozczarowanie wykazują ujemny związek z celem, spójnością wewnętrzną, kontrolą życia, a także pozytywny z pustką egzystencjalną i z poszukiwaniem celów.

4. Postawy egzystencjalne odwrotnie proporcjonalnie łączące się z wypaleniem zawodowym pełnią rolę czynników chroniących przed jego pojawieniem się.

5. Postawy życiowe pozostające w dodatnim związku z omawianym syndromem mogą nasilać ryzyko wystąpienia powyższego zespołu.

6. Uzyskane rezultaty badań własnych mają znaczenie poznawcze, a także mogą być wykorzystane do opracowania programów profilaktycznych i pomocowych wspierających jakość osobistego, a także zawodowego funkcjonowania pielęgniarek.

\section{PIŚMIENNICTWO/REFERENCES}

1. Sęk H. red. Wypalenie zawodowe. Przyczyny i zapobieganie. Warszawa: Wydawnictwo Naukowe PWN; 2012.

2. Wilczek-Rużyczka E. Wypalenie zawodowe pracowników medycznych. Warszawa: Wolters Kluwer SA.

3. Li YY, Li LP. An investigation on job burnout of medical personnel in a top three hospital. Zhonghua Lao Dong Wei Sheng Zhi Ye Bing Za Zhi. 2016; 20; 34 (5): 357-360.

4. Lewandowska A, Litwin B. Wypalenie zawodowe jako zagrożenie w pracy pielęgniarki. Rocz Pom AM. 2009; 55 (3): 86-89.

5. Queiros C, Carlotto MS, Kaiseler M et al. Predictors of burnout among nurses: An integrationists approach. Psicothema. 2013; 25 (3): 330-335.

6. Uchmanowicz I, Jankowska-Polańska B, Bronowicka G. Zjawisko wypalenia zawodowego wśród pielęgniarek pracujących na oddziałach onkologicznych badania wstępne. Probl. Pielęg. 2013; 21 (4): 476-483.

7. Santinello M. LBQ Kwestionariusz Wypalenia Zawodowego. Podręcznik. Warszawa: Pracownia Testów Psychologicznych PTP; 2014.

8. Reker GT, Peacock EJ. The Life Attitude Profile (LAP): A multidimensional instrument for assessing attitudes toward life. Can J of Behav Science. 1981; 13 (3): 264-273.

9. Reker GT, Wong PT. Aging as an individual process: Toward The theory of personal meaning. [w:] Birren JE, Bengtson VL, red. Emergent the theories of aging. New York: Springer Publishing; 1988, s. 214-246.

10. Reker GT. Life Attitude Profile - Revised (LAP-R). Ontario: Students Psychologists Press; 1992.

11. Klamut R. Kwestionariusz Postaw Życiowych KPŻ. Podręcznik do polskiej adaptacji Kwestionariusza Life Attitude Profile-Revised (LAP-R) Gary'ego T. Rekera. Warszawa: Pracownia Testów Psychologicznych PTP; 2010.

12. Jaworowska A. Kwestionariusz Wypalenia Zawodowego LBQ M. Santinello. Polska normalizacja. Warszawa: Pracownia Testów Psychologicznych PTP; 2014

13. Durkin M, Beaumont E, Hollins MCJ, Carson J. A pilot study exploring the relationship between self-compassion, self-judgment, self-kindness, compassion, professional quality of life and wellbeing among UK community nurses. Nurse Educ Today. 2016; 30 (46): 109-114.

14. Kolthoff KL, Hickman SE. Compassion fatigue among nurses working with older adults. Geriatr Nurs. 2016; 4572 (16): 154-159.

15. Lee $Y$, Seomun $G$. Role of compassion competence among clinical nurses in professional quality of life. Int Nurs Rev. 2016; 63 (3): 381-387.

16. Vander ET, Cavents C, Daneels K et al. Job demands-resources predicting burnout and work engagement among Belgian home health care nurses: A cross-sectional study. Nurs Outlook. 2016; 54 (16): 30112-30119.

17. Admi H, Eilon-Moshe Y. Do hospital shift charge nurses from different cultures experience similar stress: An international cross sectional study. Int J Nurs Stud. 2016; 26 (63): 48-57.

Praca przyjęta do druku /Manuscript received: 23.09.2016

Praca zaakceptowana do druku /Manuscript accepted: 03.11.2016

Tłumaczenie/Translation: Anna Goś 